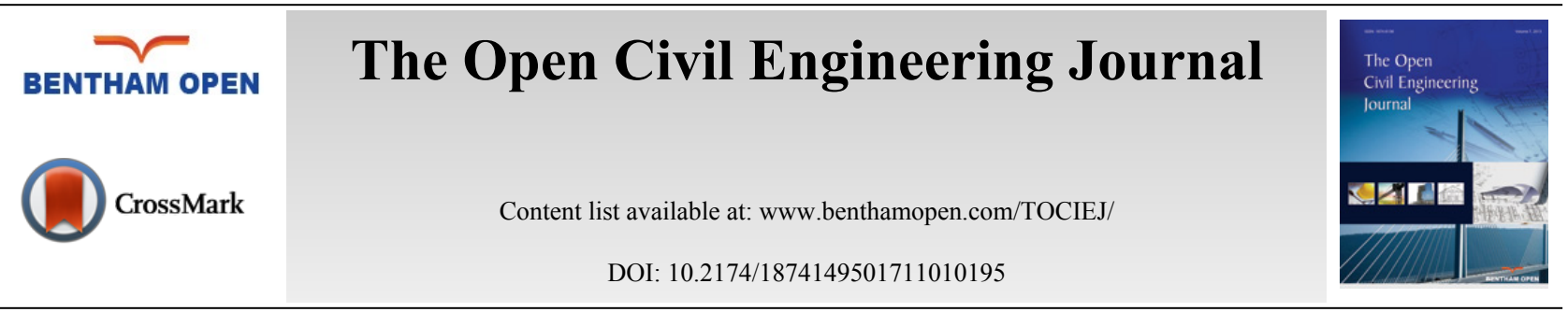

RESEARCH ARTICLE

\title{
Research on the Mode of Evacuation and Rescue by Adopting Emergency Station in Super-long Railway Tunnel
}

\author{
Nian Zhang ${ }^{1, *}$, Daqian $\mathrm{Han}^{2}$, Bo $\mathrm{Du}^{1}$ and Jianian Zhang ${ }^{1}$ \\ ${ }^{I}$ Taiyuan University of Science and Technology, Taiyuan city, China \\ ${ }^{2}$ Transportation Research Institute of Shanxi Province, Taiyuan city, China
}

Received: August 26, 2016

Revised: January 03,2017

Accepted: January 10, 2017

\begin{abstract}
By taking the super-long railway tunnel as the object of research, based on setting problems of emergency stations adopted by super-long railway tunnels, from the viewpoint of people's safe evacuation, several aspects were studied, such as the mode of evacuation and rescue by adopting emergency station, the number and interval of the cross passage, and the people's safe evacuation time under different fire scenes at the emergency station. The basis for optimal design and construction of the emergency station in the super-long railway tunnel was provided, and it has vital practical significance to the perfection of fire emergency rescue and safe evacuation plan in super-long railway tunnels.
\end{abstract}

Keywords: Super-long railway tunnel, Emergency station, Mode of evacuation and rescue, Cross passage, Disaster prevention and rescue.

\section{INTRODUCTION}

With the development of railway construction projects, the number of the tunnels that have a length of more than $3 \mathrm{~km}$ is nearly 200 in China [1,2]. The number of the long-large tunnel is increasing, and the high-altitude super-long railway tunnel comes out. The longest operating railway tunnel in China is Taihang mountain railway tunnels $(27.84 \mathrm{~km})$, and the highest altitude railway tunnel is Fenghuo mountain tunnel $(4905.4 \mathrm{~m})$. The length of a railway tunnel of Qinghai-Tibet line which is under construction is more than $30 \mathrm{~km}$ and its altitude is over $3300 \mathrm{~m}$, which belongs to the high-altitude super-long railway tunnel. This series long-large railway tunnel brought a lot of security issues. Because the length of the long-large tunnel is too long, it is difficult for the train to get away from the tunnel in a safe time. Thus, how to ensure the safety of the tunnel after the disaster occurs is a very important issue.

Tunnel is a long and narrow space structure, when fires break out in the tunnel, a lot of toxic and hot smoke will pose a threat to people's life and the structure of the tunnel, and it will also seriously affect the personnel rescuing and the firefighting work [3 - 10]. So, when the train gets fired in the tunnel, it should be pulled out of the tunnel as soon as possible. Because the length of the long-large tunnel is too long, it is difficult for the train to get away from the tunnel in a safe time, thus a fixed facility which is called emergency station is needed to set to make the train stop, put out fire and make the person evacuate immediately in the super-long tunnel. Emergency station makes the two single tunnels of the super-long railway tunnel be contact and mutual aid pattern, and it can be used as a place of fire fighting and rescue. The emergency station has many functions, such as: the junction line for the train, emergency refuge and evacuation, safety rescue, the ventilation control, and so on. Nowadays, the tunnel construction technology is getting more and more attention to the disaster prevention and rescue of the super-long railway tunnel all over the world and the emergency stations are set in several super-long railway tunnels [11, 12], such as Seikan tunnel in Japan, Gotthard tunnel in Switzerland, Guadarrama tunnel in Spain, Wushaoling tunnel and Taihang mountain tunnel in China. The design of the cross passage interval at the emergency station is based on the view point of safety at home and abroad. At present, a

\footnotetext{
* Address correspondence to this author at Taiyuan University of Science and Technology, No. 66, Waliu Road, Taiyuan City, Shanxi Province, China; Tel: +86-139-3460-2189; Fax: +86-0351-6998-128; E-mail: zhangnian1984@126.com
} 
large number of experiments and numerical simulations have been carried out to study the safe evacuation of tunnel personnel [13]. They studied the evacuation channel spacing for personnel safety in railway tunnels and in highway tunnels. However, there is not a confessed reference about the method how to select the cross passage interval as well as the setting problem of the emergency station.

Based on a super-long railway tunnel, calculation model of personnel evacuation was established to research on the mode of evacuation and rescue by adopting emergency station in the super-long railway tunnel in this paper.

\section{MODE OF EVACUATION BY ADOPTING THE EMERGENCY STATION}

When the train gets fired in the tunnel, it should be pulled out of the tunnel to put out the fire as soon as possible. But, because the length of the long-large tunnel is too long, it is difficult for the train to get away from the tunnel in a safe time. To ensure the higher security of the tunnel, it needs to set a fixed facility which is called emergency station to put out the fire and make the person evacuate immediately in the super-long railway tunnel.

It is provided [14] in China's high-speed railway tunnel technical standard: it should give priority to consider the designated evacuation mode as the mode of the disaster prevention and rescue in the super-long tunnel or the tunnel group with the length more than $20 \mathrm{~km}$, and set the fixed fire-fighting facilities and emergency exits near the emergency station.

The main content of the evacuation by the emergency station mode is that if the fire breaks out in the carriage and the situation of the fire cannot be controlled by the fire extinguishers of the carriage, it should evacuate the passengers from the fired carriage to the neighbor safe carriages and close the doors of the fired carriage subsequently. Then drive the train to the emergency station set in the tunnel and carry out the personnel evacuation and the firefighting work immediately at the emergency station.

So, if the train gets fired, it should give priority to consider the designated evacuation mode to evacuate the passengers in the super-long railway tunnel.

According to the form of the emergency station, there are two kinds of evacuation and rescue schemes:

1. With the refuge room. When the fired train stops at the emergency station, passengers should evacuate under the train crew's guidance immediately, then all the people evacuate through the cross passage between two tubes to the refuge room, after the rescue train arrived, they can evacuate from the refuge room to the safe tunnel and take the rescue train to leave the tunnel.

2. Without the refuge room. When the fired train stops at emergency station, passengers should evacuate under the train crew's guidance immediately, then all the people evacuate to the cross passages between two tubes and wait for the arrival of the rescue train, then they evacuate from the cross passage to the safe tunnel and take the rescue train to leave the tunnel.

Measures of the tunnel rescue can be concluded as the following ways:

1. People arrive at the ground directly through the emergency exit.

2. People wait in a safe area for the rescue train from the safe tunnel, then the rescue train will carry the people out of the tunnel.

3. People wait in a safe area for the rescue vehicle from the service tunnel (parallel heading, transverse passage or inclined shaft), then people will be evacuated out of the tunnel by the vehicle.

Different rescue measures can adapt to different conditions of the tunnel. However, the emergency exit meets the people evacuate directly to the ground can hardly exist in general railway tunnels, and the design of the rescue through the rescue vehicle is too complicated and quite uneconomical. So, under the possible conditions, the first consideration is to rescue people by the rescue train, because in this way people can be rescued out of tunnel in the shortest period of time.

Therefore, when the train gets fired and stops in the tunnel, it is recommended to adopt this way to rescue: people wait in a safe area for the rescue train from the safe tunnel, and to be rescued out of the tunnel by the rescue train. 


\section{THE NUMBER AND INTERVAL OF THE CROSS-PASSAGE IN THE EMERGENCY STATION}

\subsection{Theory of Safety Evacuation in the Tunnel}

In case of the fire in the tunnel, safety evacuation requires people should reach the safe region before the fire threatens people's life, that is, people's evacuation time should be shorter than the arrival time of the danger.

\subsubsection{Available safety evacuation time (ASET)}

ASET is a limited time that from the fire breaks out to the fire threatens people's life. In case of the fire in the tunnel, smoke is the main factor threatening to the security of the people. When the fire breaks out, generally take the following situations to determine the available safety evacuation time as ASET [15].

a. When the visibility is below $10 \mathrm{~m}$ at the characteristic height of human eyes.

b. When the temperature is above $80^{\circ} \mathrm{C}$ at the characteristic height of human eyes.

c. When the concentration of $\mathrm{CO}$ is above $2500 \mathrm{ppm}$ at the characteristic height of human eyes.

Any one of the three situations above reaches can be taken as ASET in the tunnel fire. Generally, the characteristic height of human eyes is $1.6 \mathrm{~m}$ on average.

\subsubsection{Required Safety Evacuation Time (RSET)}

RSET is a limited time that from the fire happens to the people arrive a safe region. This process can be divided roughly into three phases [16]: alarm, response and movement, the corresponding time called alarm time $\left(t_{\text {alarm }}\right)$, premovement time $\left(t_{\text {pre }}\right)$ and movement time $\left(t_{\text {move }}\right)$. RSET $=t_{\text {alarm }}+t_{\text {pre }}+t_{\text {move }}$.

\subsubsection{Guidelines for Safe Evacuation}

Fire Risk Assessment considers: if the available safety evacuation time is more than the required safety evacuation time in the building, the people in the building can be evacuated safely. That is: ASET $>$ RSET.

So, the safety evacuation should meet ASET $>$ RSET in case of the fire in the tunnel, it is also known as: people's evacuation time should be shorter than the danger's arrival time when fires break out in the tunnel.

\subsection{Numerical Simulation of the Evacuation}

Software called STEPS was used to establish the personnel evacuation model, aimed to simulate the process of the personnel evacuation and to analyze the evacuation time under four different fire scenes at the emergency station.

\subsubsection{Model of the Numerical Simulation}

The spacing of the cross-passage is one of the most important parameters in the design of the emergency station. According to European and Japanese experience, after the train gets fired, it can keep running for 15 20 minutes at the speed of $80 \mathrm{~km} / \mathrm{h}$. Therefore, the emergency station is set according to the distance of the fired train keep running for 15 minutes or set its location at the middle of the tunnel. Take into account the high requirement of the ventilation at the emergency station, the location of the emergency station in the tunnel should be considered with the location of the inclined shaft together. The probability of the train cannot arrive at the emergency station under a different number and a different distance of the emergence station was simulated in the security design of Gotthard tunnel to determine the set of its emergency station number and location [17 - 19]. Setting of the emergency station is shown as Table 1.

Table 1. Setting of the emergency station all over the world.

\begin{tabular}{|c|c|c|c|c|c|}
\hline Tunnel name & Length of the tunnel & $\begin{array}{c}\text { Number of the } \\
\text { emergency station }\end{array}$ & $\begin{array}{c}\text { Length of the } \\
\text { emergency station }\end{array}$ & $\begin{array}{c}\text { Interval of the } \\
\text { cross passage }\end{array}$ & \begin{tabular}{c} 
Location of the emergency station \\
\hline Seikan Tunnel
\end{tabular} \\
\hline Gotthard Tunnel & $53.85 \mathrm{~km}$ & 2 & $480 \mathrm{~m}$ & $40 \mathrm{~m}$ & $23 \mathrm{~km}$ between two stations \\
\hline Guadarrama Tunnel & $28.4 \mathrm{~km}$ & 2 & $516 \mathrm{~m}$ & $86 \mathrm{~m}$ & $16 \mathrm{~km}$ between two stations \\
\hline Wushaoling Tunnel & $20.05 \mathrm{~km}$ & 1 & $500 \mathrm{~m}$ & $50 \mathrm{~m}$ & Middle of the tunnel \\
\hline Taihangshan Tunnel & $27.84 \mathrm{~km}$ & 1 & $560 \mathrm{~m}$ & $70 \mathrm{~m}$ & Middle of the tunnel \\
\hline
\end{tabular}

In order to select the rational spacing of the cross-passage in the emergency station, according to the experiences of 
the emergency station in China and abroad which can be seen in the Table 1, we select different spacing of the crosspassage such as $50 \mathrm{~m}, 60 \mathrm{~m}, 70 \mathrm{~m}$ and $80 \mathrm{~m}$ in the numerical simulation which is calculated by STEPS to simulate different evacuation scenes.

In this study, the prototype of the calculation model is the super-long railway tunnel in the Qinghai-Tibet railway line. According to the design parameters of Guanjiao tunnel, it set the effective width of the evacuation platform in the emergency station to be $2.5 \mathrm{~m}$ in the numerical model.

Arrangement of the emergency station in the simulation, please refer to Fig. (1).

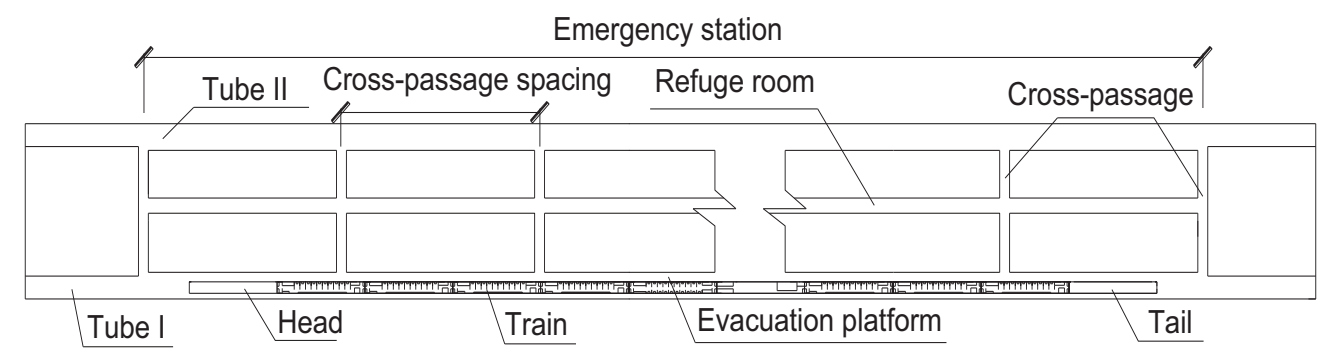

Fig. (1). Arrangement of the emergency station.

Parameters of the emergency station under different passage spacing, please refer to Table 2.

Table 2. Parameters of the emergency station under different passage spacing.

\begin{tabular}{|c|c|c|c|c|}
\hline $\begin{array}{c}\text { Passage spacing } \\
(\mathbf{m})\end{array}$ & $\begin{array}{c}\text { Length of the emergency } \\
\text { station } \mathbf{( m )}\end{array}$ & $\begin{array}{c}\text { Number of the cross- } \\
\text { passage }\end{array}$ & $\begin{array}{c}\text { Effective width of the cross- } \\
\text { passage (m) }\end{array}$ & $\begin{array}{c}\text { Effective width of the } \\
\text { evacuation platform (m) }\end{array}$ \\
\hline 50 & 500 & 11 & 3 & 2.5 \\
\hline 60 & 480 & 9 & 3 & 2.5 \\
\hline 70 & 490 & 8 & 3 & 2.5 \\
\hline 80 & 480 & 7 & 3 & 2.5 \\
\hline
\end{tabular}

According to the design of the train for Qinghai-Tibet Plateau [20], total length of the train is $450 \mathrm{~m}$, there are five kinds of carriages in the Qinghai-Tibet railway passenger train: hard seat carriage, hard sleeper carriage, soft sleeper carriage, dining carriage and power carriage. Specific parameters as shown in the following Table 3.

Table 3. Parameters of the train.

\begin{tabular}{|c|c|c|c|c|c|c|}
\hline \multirow{2}{*}{ Parameters } & \multirow{2}{*}{ Hard seat carriage } & \multicolumn{2}{|c|}{ Hard sleeper carriage } & \multirow{2}{*}{ Soft sleeper carriage } & \multirow{2}{*}{ Dining carriage } & \multirow{2}{*}{ Power carriage } \\
\cline { 3 - 6 } & & Normal & Special & & 1 & 1 \\
\hline Number of carriage & 4 & 7 & 1 & 2 & 44 & 0 \\
\hline Number of people & 98 & 60 & 54 & 32 & 44 & 0 \\
\hline \multirow{2}{*}{ Total } & 392 & 420 & 54 & 64 & \multicolumn{2}{l}{} \\
\cline { 2 - 7 }
\end{tabular}

\subsubsection{Scenes of the Numerical Simulation}

According to the different evacuation requirements, the authors consider two kinds of evacuation mode: 1) The people evacuate to the refuge room; 2) The people evacuate to the cross-passage.

According to the development of the fire when the train is arriving at the emergency station, we consider two kinds of fire development: a) The smoke temperature is low (It means the fire is in its early stages of development.); b) The smoke temperature is high (It means the fire is broke out.).

In order to analyze the personnel evacuation at the emergency station under different conditions, the authors select four fire scenes to perform the simulation: A) Persons evacuate to the refuge room when the smoke temperature is high; B) Persons evacuate to the refuge room when the smoke temperature is low; C) Persons evacuate to the cross-passage when the smoke temperature is high; D) Persons evacuate to the cross-passage when the smoke temperature is low.

\subsubsection{Parameters of the People in the Calculation}

1) Characteristic parameters of the people. 
The personnel load in the calculation is designed according to the full load, and according to the design of the train for Qinghai-Tibet Plateau, the total personnel number of full load is 974 [21, 22]. Besides, via the statistics and analysis of the passengers in the train, and consider in the aspect of simplifying the simulation, the authors can group the train passengers according to their age, and they can be divided into three groups: old people, young people and children [23]. Characteristic parameters of the people in the simulation, please refer to Table 4.

Table 4. Characteristic parameters of the people set in the simulation.

\begin{tabular}{|c|c|c|c|c|}
\hline Type of the people & Width $(\mathbf{m})$ & Depth $(\mathbf{m})$ & Height $(\mathbf{m})$ & Patience level \\
\hline Young people & 0.45 & 0.3 & 1.75 & High \\
\hline Old people & 0.4 & 0.25 & 1.70 & Middle \\
\hline Children & 0.3 & 0.2 & 1.40 & Low \\
\hline
\end{tabular}

2) Evacuation velocity setting.

Evacuation velocity of the people is very important to this research. In order to get a true speed of passengers, the authors took a real test at Beijing west railway station. It can be seen Fig. (2).
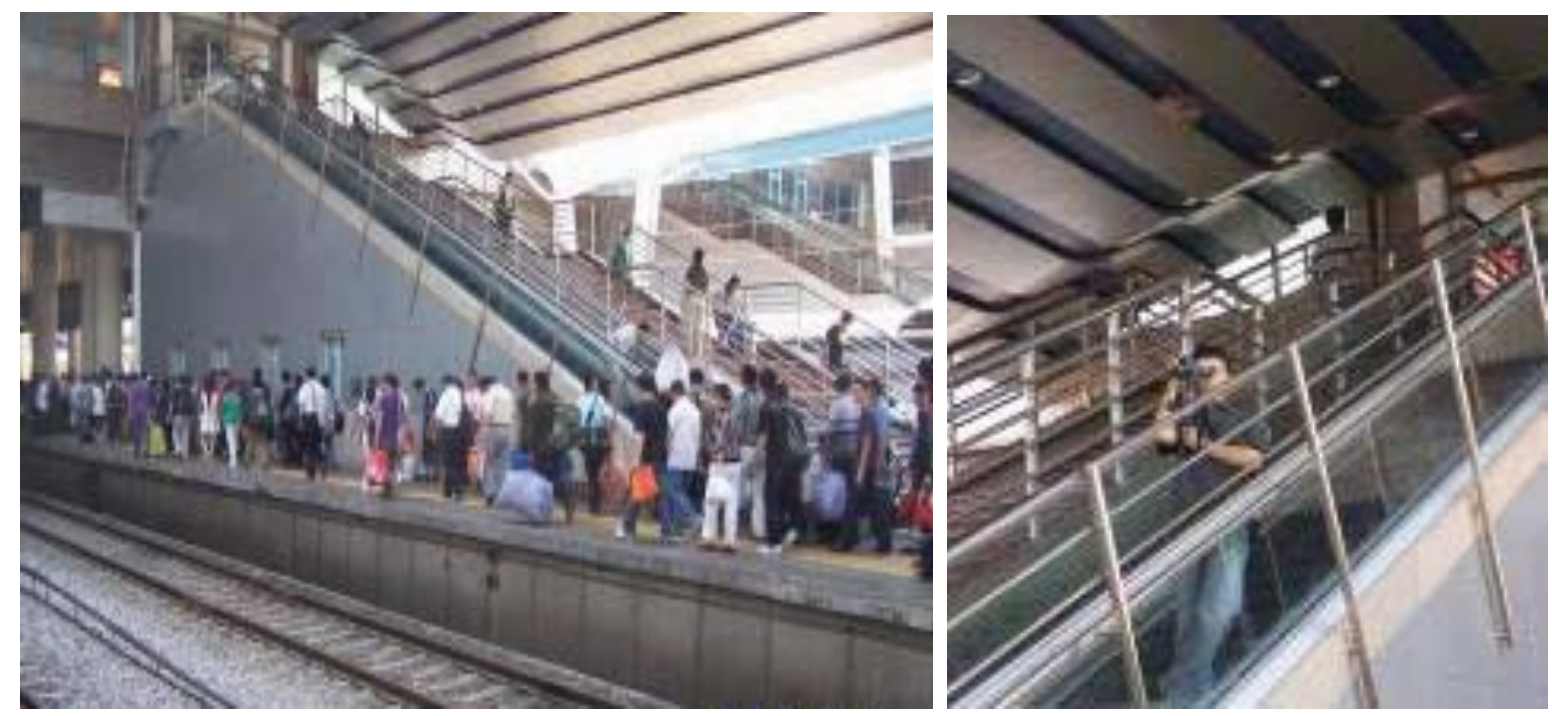

Fig. (2). Test at the railway station.

Through the test, the authors got the total time that the passengers left the platform was 5 minutes and the total move distance of the passengers was 230 meters. By simple calculation, you can get the average speed of the people move on the platform was about $0.9 \mathrm{~m} / \mathrm{s}$. But, this is the velocity without the influence of the smoke.

Smoke can bring many negative effects on the people, such as walking velocity, psychology as well as the judgment ability. The influence would be much more severe as the smoke concentration increasing. According to research at home and abroad [24, 25], people's evacuation velocity is $0.4 \sim 0.9 \mathrm{~m} / \mathrm{s}$ under the flue gas condition.

Altitude more than $3000 \mathrm{~m}$ is called the plateau region. Plateau region is characterized by low air pressure and the concentration of oxygen in air is also low, easily lead to human hypoxia. Within a short time to enter more than $3000 \mathrm{~m}$ altitude can produce headache, dizziness, palpitations, shortness of breath and other reactions. At an altitude of 5500m height, a person's ability to complete the exercise is reduced to 50\% [26]. This super-long railway tunnel is at an altitude of over 3300 meters, belonging to plateau region, people's physiology will be influenced by the high altitude.

To verify the effects of high altitude and smoke on the personnel evacuation velocity under the tunnel fire, the authors took a simple walking test in the high-altitude tunnel under a fire. It can be seen in Fig. (3) below. 


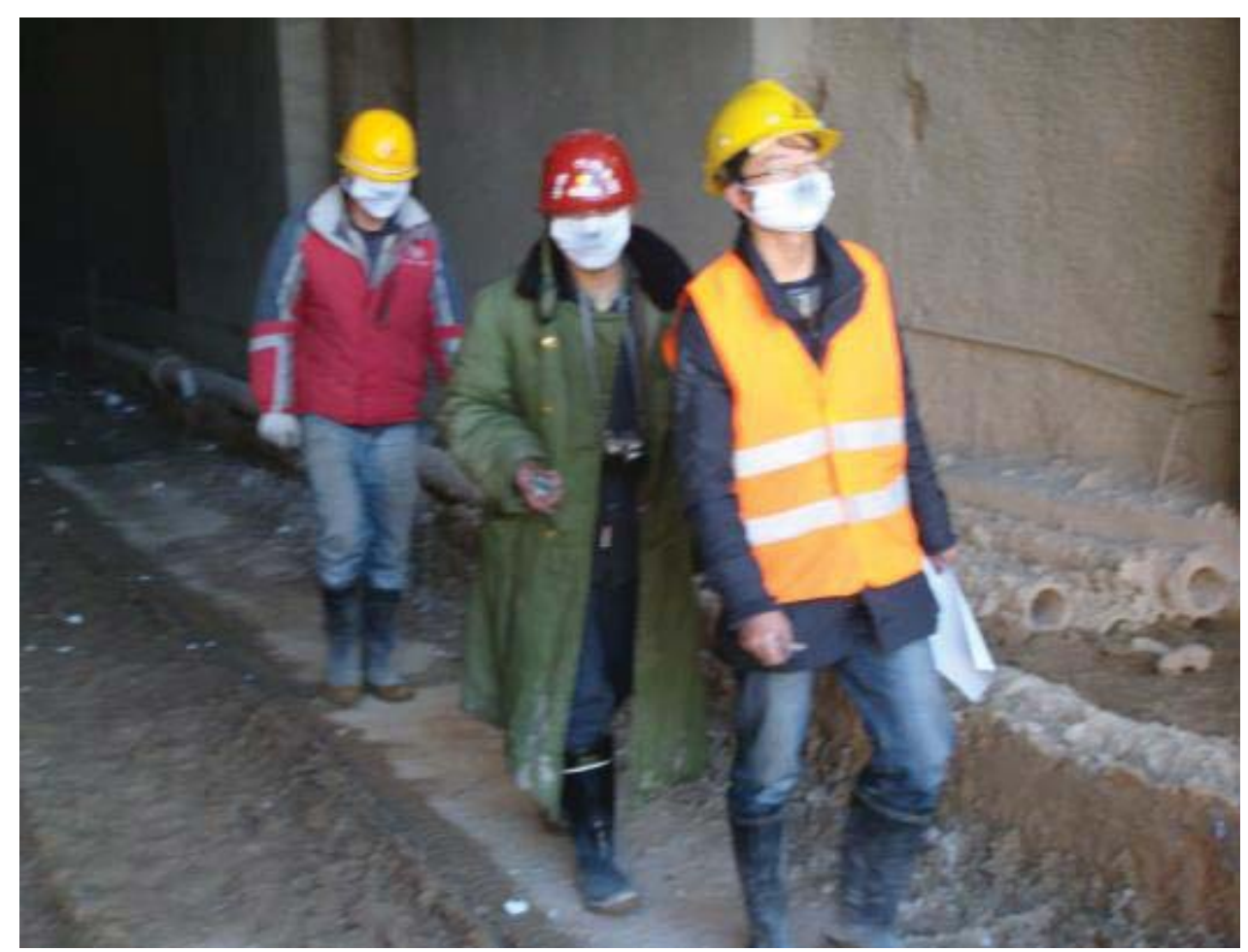

Fig. (3). Walking test in the high-altitude tunnel under a fire.

When testers were walking in the tunnel, the smoke filled the tunnel fully, but the smoke concentration was not high. The length of the test was just 120 meters, but testers walked nearly 3 minutes. By simple calculation, you can get the average speed of the people move in the tunnel was about $0.7 \mathrm{~m} / \mathrm{s}$. But, it is the velocity in the case of lighting. If there is no light, the velocity will be much lower.

After comprehensive consideration, given evacuation velocity relative to the low-altitude area multiplied by the conversion factor of 0.8 , then the evacuation velocity under the high altitude smoke condition is $0.32 \sim 0.72 \mathrm{~m} / \mathrm{s}$.

All the researches organized adults in the test to get the evacuation velocity without considering the children, the elderly and disabled groups. So, in the simulation, given evacuation velocity of children and old people relative to adults multiplied by the conversion factor of 0.8 and 0.6 .

For greater safety factor, the authors will choose a relatively conservative calculation velocity. The velocity of the people (Young people) is set to be $0.4 \mathrm{~m} / \mathrm{s}$ and $0.6 \mathrm{~m} / \mathrm{s}$ under the different tunnel fire scenes. Evacuation velocity of the people under different scenes in the simulation is shown as Table $\mathbf{5}$.

Table 5. Evacuation velocity of the people in the simulation.

\begin{tabular}{|c|c|c|}
\hline \multirow{2}{*}{ Type of the people } & \multicolumn{2}{|c|}{ Evacuation velocity under different scenes (m/s) } \\
\cline { 2 - 3 } & Scene A and Scene C & Scene B and Scene D \\
\hline Young people & 0.4 & 0.6 \\
\hline Children & 0.32 & 0.48 \\
\hline Old people & 0.24 & 0.36 \\
\hline
\end{tabular}

\subsection{Evacuation Simulation Results and Analysis}

\subsubsection{Evacuation Simulation Results}

1) The relationship between the evacuation time and the number of evacuated people under different fire scenes are shown as Fig. (4). 

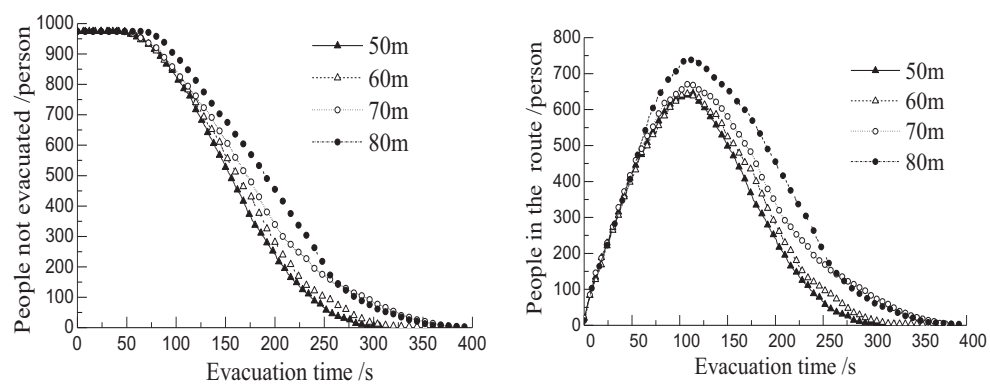

Fig. 4a. Correlation curve for the number of people and evacuation time under scene A
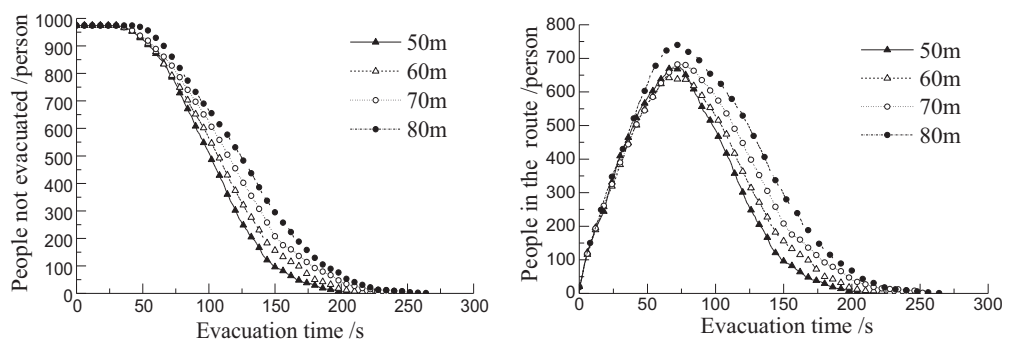

Fig. 4b. Correlation curve for the number of people and evacuation time under scene B
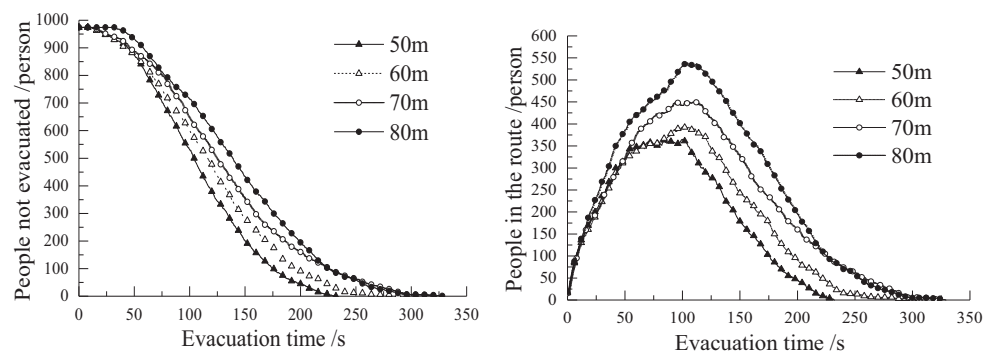

Fig. 4c. Correlation curve for the number of people and evacuation time under scene $\mathrm{C}$
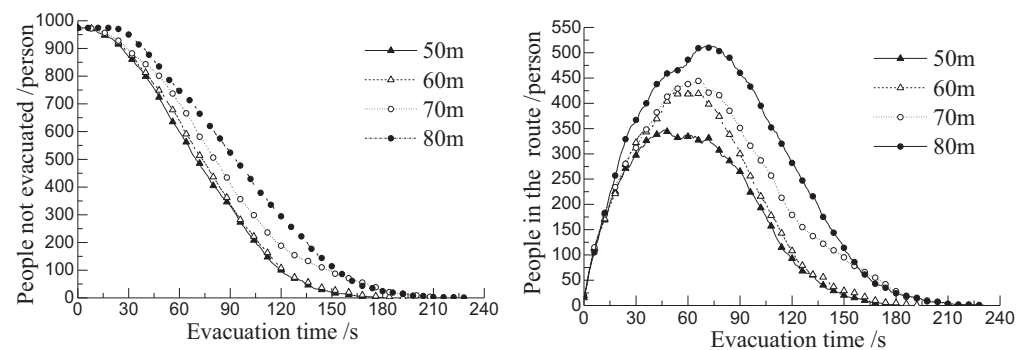

Fig. 4d. Correlation curve for the number of people and evacuation time under scene D

Fig. (4). Correlation curve for the number of people and evacuation time under different scenes.

2) Comparison of the evacuation time under different scenes and different cross passage intervals is shown as Table 6.

Table 6. Comparison of the evacuation time under different scenes.

\begin{tabular}{|c|c|c|c|c|}
\hline Cross passage interval & $\mathbf{5 0 m}$ & $\mathbf{6 0 m}$ & $\mathbf{7 0 m}$ & $\mathbf{8 0 m}$ \\
\hline Scene A & $313 \mathrm{~s}$ & $364 \mathrm{~s}$ & $388 \mathrm{~s}$ & 396 \\
\hline Scene B & $215 \mathrm{~s}$ & $240 \mathrm{~s}$ & $254 \mathrm{~s}$ & 266 \\
\hline Scene C & $252 \mathrm{~s}$ & $307 \mathrm{~s}$ & $320 \mathrm{~s}$ & $333 \mathrm{~s}$ \\
\hline Scene D & $179 \mathrm{~s}$ & $194 \mathrm{~s}$ & $214 \mathrm{~s}$ & $230 \mathrm{~s}$ \\
\hline
\end{tabular}


3) Curves for comparisons of maximum density of people under different cross-passage spacing and different scenes, please refer to Fig. (5).

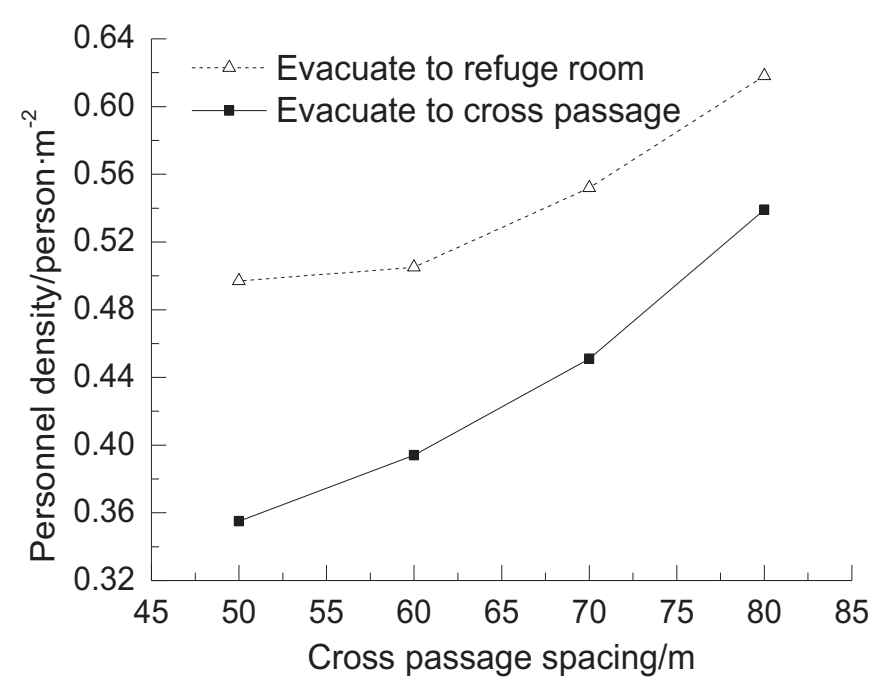

Fig. (5). Curves for comparisons of e maximum density of people under different cross-passage spacing and different scenes.

\subsubsection{Analysis of Simulation Results}

From Fig. (4) and Table 6, it can be seen, the evacuation time is different as the cross passage intervals are different, and the evacuation time changes as fire scenes change. The evacuation time under the high smoke temperature fire scene (broke out) is more than the low smoke temperature fire scene (early stages of development). Although the evacuation time increases as the cross passage interval increases, the most evacuation time is 396s. Taking 6 minutes (360s) as ASET when fires break out in tunnel, almost all the cross passage intervals can meet the standard of the safety evacuation.

From Figs. (4 and 5), it can be seen, the number of people don't evacuate in the tunnel is different as the cross passage intervals are different, and the evacuation time changes as fire scenes change. When the people's evacuation velocity is lower, the number of the people didn't evacuate in the tunnel is more and the larger the cross passage interval is, the more the number of the people don't evacuate in the tunnel is. The peak number of the people in the tunnel is 756 , and then the available area of the evacuation route is $1200 \mathrm{~m}^{2}$, so the maximum density of the people is 0.63 person $/ \mathrm{m}^{2}$. The density of the people distribution is not large, and the evacuation route will not occur within the congestion and block phenomenon.

Results show that the utilization of the head and the tail cross passages are 0 under the different cross passage intervals, so the authors can consider removing both the head and the tail cross passages to reduce the number of the cross passage, and to optimize the design.

Therefore, results show almost all the several cross passage intervals selected in the numerical simulation can meet the safety evacuation under different fire scenes at the emergency station, but for actual selection of the emergency station setting of this high-altitude super-long tunnel should consider much more comprehensive factors. Considering factors of the complex environment and the engineering economy, the cross passage interval of the emergency station in the tunnel is recommended to be $60 \mathrm{~m}$.

\section{CONCLUSION}

By taking the super-long railway tunnel as the research object, a large number of numerical simulation has been taken in the paper, aiming to solve problems of the emergency station design of the super-long railway tunnel, such as the number, the location and the length of the emergency station, the number and the interval of the cross passage, and the people's safety evacuation time under different fire scenes at the emergency station. The mode of evacuation and rescue by adopting emergency station is summarily discussed and summarized. Here are the several conclusions as follows: 
1. The super-long railway tunnel is recommended to set emergency stations in the design of its disaster prevention and rescue and the disaster prevention and rescue mode should give priority to consider the designated evacuation mode and adapt the rescue train to rescue.

2. According to the calculation result, both kinds of emergency station form setting can meet the available safety evacuation time, from the viewpoint of greater security, the recommended design contains the refuge room. There is better security equipment which can enhance the security of the rescue facilities. So, considering the higher security, the form of the emergency station is recommended to be the form with refuge room.

3. Considering factors of the complex environment and the engineering economy, the cross passage interval of the emergency station in the tunnel is recommended to be $60 \mathrm{~m}$.

The scheme of the emergency station setting of the super-long railway tunnel was decided, the basis of further optimize the design and the construction was provided, and it has vital practical significance to the perfection of fire emergency rescue and safe evacuation plan in super-long railway tunnels.

\section{CONFLICT OF INTEREST}

The authors confirm that this article content has no conflicts of interest.

\section{ACKNOWLEDGEMENTS}

This work is sponsored by the Youth Fund of Taiyuan University of Science and Technology (20153014) which is gratefully acknowledged.

\section{REFERENCES}

[1] M.S. Wang, "An overview of development of railways, tunnels and underground works in China", Tunnel Constr., vol. 30, no. 4, pp. 351-364, 2010 .

[2] C. He, and B. Wang, "Research progress and development trends of highway tunnels in China", J. Mod. Transp., vol. 21, no. 4, pp. 209-223, 2013.

[http://dx.doi.org/10.1007/s40534-013-0029-4]

[3] W.K. Chow, "Simulation of tunnel fires using a zone model", Tunn. Undergr. Space Technol., vol. 11, no. 2, pp. 221-236, 1996. [http://dx.doi.org/10.1016/0886-7798(96)00012-0]

[4] A. Haack, "Fire protection in traffic tunnels: general aspects and results of the EUREKA Project", Tunn. Undergr. Space Technol., vol. 13, no. 4, pp. 377-381, 1998. [http://dx.doi.org/10.1016/S0886-7798(98)00080-7]

[5] Y. Wu, and M.Z. Bakar, "Control of smoke flow in tunnel fires using longitudinal ventilation systems - a study of the critical velocity", Fire Saf. J., vol. 35, no. 4, pp. 363-390, 2000.

[http://dx.doi.org/10.1016/S0379-7112(00)00031-X]

[6] H. Kurioka, Y. Oka, H. Satoh, and O. Sugawa, "Fire properties in near field of square fire source with longitudinal ventilation in tunnels", Fire Saf. J., vol. 38, no. 4, pp. 319-340, 2003.

[http://dx.doi.org/10.1016/S0379-7112(02)00089-9]

[7] S. Bari, and J. Naser, "Simulation of smoke from a burning vehicle and pollution levels caused by traffic jam in a road tunnel", Tunn. Undergr. Space Technol., vol. 20, no. 3, pp. 281-290, 2005. [http://dx.doi.org/10.1016/j.tust.2004.09.002]

[8] L.H. Hu, R. Huo, Y.Z. Li, H.B. Wang, and W.K. Chow, "Full-scale burning tests on studying smoke temperature and velocity along a corridor", Tunn. Undergr. Space Technol., vol. 20, no. 3, pp. 223-229, 2005. [http://dx.doi.org/10.1016/j.tust.2004.08.007]

[9] G.S. Yang, L.M. Peng, and Y.L. An, "Study on spacing between vehicles and passages of road tunnel", J. Cent. South Univ., vol. 53, no. 2, pp. 362-367, 2007. [Science and Technology].

[10] A.N. Bear, "Fire safety in tunnels", Fire Saf. J., vol. 44, no. 2, pp. 276-278, 2009. [http://dx.doi.org/10.1016/j.firesaf.2008.06.008]

[11] R.O. Carvel, A.N. Beard, and P.W. Jowitt, "The influence of longitudinal ventilation systems on fires in tunnels", Tunn. Undergr. Space Technol., vol. 16, no. 1, pp. 3-21, 2001. [http://dx.doi.org/10.1016/S0886-7798(01)00025-6]

[12] F. Vuilleumier, A. Weatherill, and B. Crausaz, "Safety aspects of railway and road tunnel: example of the Lötschberg railway tunnel and Mont-Blanc road tunnel", Tunn. Undergr. Space Technol., vol. 17, no. 2, pp. 153-158, 2002. [http://dx.doi.org/10.1016/S0886-7798(02)00018-4]

[13] D. Nilsson, M. Johansson, and H. Frantzich, "Evacuation experiment in a road tunnel: A study of human behavior and technical installations", 
Fire Saf. J., vol. 44, no. 4, pp. 458-468, 2009.

[http://dx.doi.org/10.1016/j.firesaf.2008.09.009]

[14] C. Guo, M.N. Wang, and H.D. Zhao, "Research on the emergency rescue of fire in super-long railway tunnel", China Safety Science Journal, vol. 17 , pp. 154-158, 2007.

[15] N. Zhang, and Z.S. Tan, "Numerical simulation study on the smoke distribution of fire in high-altitude super-long railway tunnels", China Saf. Sci. J., vol. 23, no. 6, pp. 52-57, 2013.

[16] W.C. Fan, J.H. Sun, and S.X. Lu, Methodology of Fire Risk Evaluation., Scientific Press: Beijing, 2004.

[17] S. Matsuo, "An overview of the Seikan tunnel project", Tunn. Undergr. Space Technol., vol. 1, no. 3, pp. 323-331, 1986. [http://dx.doi.org/10.1016/0886-7798(86)90015-5]

[18] D. Diamantidis, F. Zuccarelli, and A. Westhäuser, "Safety of long railway tunnels", Reliab. Eng. Syst. Saf., vol. 67, no. 2, pp. 135-145, 2000. [http://dx.doi.org/10.1016/S0951-8320(99)00059-9]

[19] N. Zhang, Z.S. Tan, and M.J. Jin, "Research on the technology of disaster prevention and rescue in high-altitude super-long railway tunnel", KSCE J. Civ. Eng., vol. 19, no. 3, pp. 756-764, 2015. [http://dx.doi.org/10.1007/s12205-013-1248-2]

[20] Y.D. Liu, L.X. Song, and J.B. Zang, "Research on the issue of fire prevention of train for Qinghai-Tibet Railway", Diesel Locomot., vol. 39, no. 5, pp. 1-4, 2004.

[21] J.A. Capote, D. Alvear, O. Abreu, and A. Cuesta, "Analysis of evacuation procedures in high speed trains fires", Fire Saf. J., vol. 49, pp. 35-46, 2012. [http://dx.doi.org/10.1016/j.firesaf.2011.12.008]

[22] N. Zhang, "Research on Combustion Characteristics and Safety Evacuation of High-altitude Super-Long Railway Tunnel", Ph.D. dissertation, Beijing Jiaotong University, Beijing, China, 2012.

[23] J.J. Fruin, Pedestrian Planning and Design., Metropolitan Association of Urban Designers and Environmental Planners Inc, 1971.

[24] J. Gu, "The evacuation and rescue in subway tunnel fire", Labor Prot., vol. 10, no. 2, pp. 70-71, 2004.

[25] D.H. Kim, and W.H. Park, "Experiment by using reduced scale models for the fire safety of a rescue station in very long rail tunnel in Korea", Tunn. Undergr. Space Technol., vol. 21, no. 3, pp. 303-303, 2006. [http://dx.doi.org/10.1016/j.tust.2005.12.159]

[26] Kang, "Comparison of high altitude, plain training and partial physiological indexes of world plateau athletes", J. Tianjin Inst. Phys. Educ., no. 3, pp. 155-158, 2008.

(C) 2017 Zhang et al.

This is an open access article distributed under the terms of the Creative Commons Attribution 4.0 International Public License (CC-BY 4.0), a copy of which is available at: (https:/creativecommons.org/licenses/by/4.0/legalcode). This license permits unrestricted use, distribution, and reproduction in any medium, provided the original author and source are credited. 